\title{
The Stoic Monastic: Taiwanese Buddhism and the Problem of Emotions
}

Hillary Crane

Linfield College

Follow this and additional works at: https://digitalcommons.linfield.edu/soanfac_pubs

Part of the Social and Cultural Anthropology Commons

\section{DigitalCommons@Linfield Citation}

Crane, Hillary, "The Stoic Monastic: Taiwanese Buddhism and the Problem of Emotions" (2006). Faculty Publications. Published Version. Submission 3.

https://digitalcommons.linfield.edu/soanfac_pubs/3

This Published Version is protected by copyright and/or related rights. It is brought to you for free via open access, courtesy of DigitalCommons@Linfield, with permission from the rights-holder(s). Your use of this Published Version must comply with the Terms of Use for material posted in DigitalCommons@Linfield, or with other stated terms (such as a Creative Commons license) indicated in the record and/or on the work itself. For more information, or if you have questions about permitted uses, please contact digitalcommons@linfield.edu. 


\title{
The Stoic Monastic: Taiwanese Buddhism and the Problem of Emotions
}

\author{
Hillary CRANE
}

\begin{abstract}
This paper explores the stoicism of Taiwanese monastics and argues that, in this context, emotions are believed to be dangerous in part because they interfere with spiritual cultivation. A stoic exterior further represents an inner state of calm and a lack of emotionality. Since women are believed to have more emotional problems than men, nuns in particular seek to control their emotions, in part by studying the example of monks. Women's emotions are contrasted with the trait of compassion, which is associated with men and thought to be selfless. Cultivating compassion is the focus of much of their spiritual practice and at the center of the vow taking ceremony, wherein they burn scars into their foreheads, signaling their compassion and willingness to endure the world's suffering, and also concretizing the abstract emotion of compassion through bodily pain.
\end{abstract}

\section{Introduction $^{1}$}

Taiwanese Buddhist monastics have a stoic demeanor. They are quite serious and rarely joke or smile, unlike Buddhist monastics in many other parts of Asia. They wear grey and black, they walk with perfect posture,

Hillary Crane received her Ph.D. in Anthropology from Brown University. She is currently a visiting scholar at Tufts University. Her e-mail address is Hillary. Crane@tufts.edu 
and they rarely smile. In contrast to many images of Buddhism familiar to Westerners, such as the frequently seen images of the rotund Maitreya or monks in other parts of Asia who tell jokes or seem giddy, Taiwanese monastics can at first seem dour and humorless. Looks can be deceiving, however, and while Taiwanese monastics are certainly earnest, it would be a disservice to describe them as uniformly cold and unwelcoming. Once I got to know them, during my ethnographic field research at a large monastery in central Taiwan, I found that they could be quite funny, especially one on one but also when lecturing to a large community. Many Taiwanese monastics are in fact quite charming, particularly those who hold leadership positions that involve a great deal of lay community exposure. One nun I took meditation classes from at an urban branch meditation center was one of the most charismatic people I have ever encountered; her charisma was most clearly evinced by the large number of lay people who decided to take up the monastic life after being inspired by her ease and charm while taking her classes. Nevertheless, the majority of Taiwanese Buddhist monastics are quite serious and embody stoicism. They exude self-control, not only in their calm, impassive faces, but also in their gait and posture. ${ }^{2}$

Although all monastics have the same basic appearance - the same clothing, countenance, and shaved head - those who have taken their final vows also have three coin-sized scars burned into their scalps just above their foreheads. For those who took their final vows some time ago, these are pale scars whose color stands out even when the head is freshly shaved, but even more so when surrounded by stubble. When the scars are new, they appear quite painful as scabs that are plain to see. They serve as reminders of the Bodhisattva vow to endure limitless pain to ensure the liberation of all sentient beings from the wheel of reincarnation.

In this paper I explore what these aspects of monastic appearance reveal about monastics' need both to control their emotions and to cultivate compassion, and I situate each aspect in different discourses within the literature on the anthropology of emotion. I argue first that stoicism has different meanings here than in other cultural contexts. Second, I show that emotions are perceived as dangerous in the monastery, but for different reasons than in other Chinese contexts, and that they are particularly dangerous for women. Finally, I argue that compassion can be written on the body and, through physical pain and scarification, one's lived experience of emotion can be dramatically altered. 


\section{Emotional Mastery}

In this section, I examine self-mastery cross-culturally, and subsequently show that the Taiwanese monastic context holds different expectations and assigns different meanings to stoicism than those of other societies. By comparing the monastic emphasis on self-control with anthropological literature from other contexts where emotional self-mastery is lauded, I examine larger questions of what it means to be in control of one's emotions in the monastery context - where showing any emotion, even joy, would reveal that one can be affected by emotion.

\section{Emotional Mastery in Cross-Cultural Perspective}

Anthropological studies of other communities suggest that self-control over one's emotions is a central value in many societies. In these societies, the importance of the appearance of emotional self-control is a common trait, and the meaning of self-control and the value given to the emotional content that is restrained is also quite similar. However, as I show below, Taiwanese Buddhist monastics differ considerably from other cultural contexts where emotional self-mastery is encouraged.

Michelle Rosaldo's (1980) study of the Ilongot of the mountainous forests of the Philippines analyses their cultural beliefs about emotion including the value of self-control. Rosaldo discusses in depth the native concept of liget, which could be rendered in English several ways including as "heat," "anger," or "energy." It connotes a depth and power to feeling which is amplified in key emotional times, such as in grief. Although liget is highly valued, it is also thought best tempered by beya, a concept akin to the English word wisdom and which Rosaldo translates as "knowledge." Beya serves to balance liget and channel it in appropriate directions. This balancing of beya and liget can happen within one individual; on a headhunting raid, for instance, beya comes into play, keeping energy and excitement (liget) in check and providing one with the patience to remain hidden. It can also work between individuals or between groups of people, as when elders use their beya to reign in the liget of the young. Both qualities are desired, but the beya serves to keep the liget from amplifying beyond control. If liget is understood as the force of powerful emotions, beya is the strength and mastery to keep liget appropriately channeled.

On the Pacific atoll of Ifalk, Catherine Lutz (1988) found that two 
emotions were particularly highly valued - metagu (fear or anxiety) and song ("righteous anger"). Unlike Western societies, which privilege thought over emotion (and values those who can use rationality to control emotion), on Ifalk, no distinction is made between thought and emotion. Repiy (social intelligence) enables one to experience metagu, song, and other proper thought-emotions, which serve to promote correct moral action. Metagu keeps one appropriately subordinate to authority, while song similarly serves to channel thought-emotion in culturally approved directions. Repiy provides one the moral judgment to control which thought-emotions are acted upon, providing valued self-control.

'Agl, or "reason," provides emotional control for the Bedouin society of Awlad "Ali studied by Lila Abu-Lughod (1986). According to AbuLughod, for this community the use of ghinn, wa poetry allows one to reveal profound feelings in a culturally condoned way that demonstrates that one has ' $a g l$ and, therefore, the self-mastery to not be overwhelmed by emotion. Ghinn,wa differs sharply from emotionally revealing behavior; both point to profound emotions, but where the latter causes one to lose honor, the former enables one to gain honor, by revealing the extent and depth of the emotion being restrained by 'agl. Whereas remaining stoic says little in itself about emotional mastery (one might not be showing emotion because one is not feeling anything profound), ghinn, wa poems reveal that the appearance of stoicism requires tremendous effort, because of the depth of the feelings that are being hidden.

In each of these examples, emotional mastery gains its significance in part because of what is restrained. Holding back emotions that are not profound does not require (or reveal) strength of character, but feeling something keenly and keeping that feeling from manifesting reveals great self-control. Emotional self-control seems to earn its value in these societies when it is thought to require effort because of the power of the emotion being held back. In these contexts, feeling emotions does not connote a character flaw, only failing to restrain them does; restraining or appropriately channeling powerful emotions earns one respect and honor.

\section{Reading Emotional Mastery in Taiwanese Buddhism}

In contrast to the communities mentioned above, where one is lauded for having the force to restrain strong emotions, for monastics an appearance of calm is similarly important, but their outward appearance is supposed to mirror an interior state of calm. Rather than appearing unaffected by strong 
emotions that exist below the surface, the point in this context is to not be affected at all. Part of the spiritual practice in Taiwanese Buddhism involves learning to feel less; what Taiwanese Buddhists value is stoicism that demonstrates spiritual advancement to the point where one does not get emotional at personal situations, rather than stoicism that keeps deep and powerful emotions from being seen.

When explaining the goal of spiritual cultivation, and particularly of exercises such as meditation, monastics often use the metaphor of an internal sea. According to this metaphor, we all have a sea within us; our true inner natures and the nature of reality would be visible to us if we could see through the depths of this water, but the surface of the water gets churned up with turbulent emotions and thoughts. Spiritual cultivation helps us learn how to calm those waters, how to experience emotions less forcefully, and how to control our thoughts, allowing us to reach that inner state of calm that enables us to see below the surface of the seas inside.

At Zhi Guang Shan, ${ }^{3}$ a large Chan Buddhist monastery where I conducted ethnographic field research, the importance of reducing the force of one's emotions was regularly discussed. My first encounter with this kind of discourse beyond the metaphor described above was when I visited the temple during a week-long silent meditation retreat. Although we were not supposed to speak during the entire week, we were allowed to seek out meditation guidance from one of the monastics leading the retreat. My grandmother passed away days before I went on the retreat, and as a result, I was distracted by my feelings of grief and thoughts about her during meditation. I asked one of the nuns what I should do. She encouraged me to rely on the counting method, which was the main meditation technique taught at the temple, to train myself not to think about her and not to feel the emotions of grief. Although clearly it was important that I not demonstrably grieve, because to do so would disturb my fellow retreaters, the emphasis of her meditation guidance was to teach me techniques for preventing myself from feeling those emotions as strongly or, better, from feeling them at all. Here, emotional restraint and an appearance of calm were less important than actually learning to feel less.

While training oneself to feel less was something that the monastics tried to teach to the lay community, it was also central to their own practice. For example, shortly after moving into the monastery, I was in a small room with about five nuns who were having tea. One was the counselor for the monastery's women's college - a young, insightful nun who the other nuns at the college (and to a lesser extent other nuns 
associated with the monastery) could seek out to discuss their problems. She provided answers, usually based on dogma, to their concerns. On this occasion, a nun sought her advice about a problem she was having: she could not stop thinking about how desperately she wanted to become a bodhisattva. Although this was of course a valid pursuit in this context, the passion with which she felt the longing was judged inappropriate. She said she knew that her desire was actually getting in the way of her progress. She described not being able to meditate, eat, or even fall asleep without thinking about how much she craved spiritual advancement. She said, exasperated, "wo yizhi xiang 'wo hao xiangyao cheng fo!'” (I constantly think "I really want to become a Buddha!"), and began to quietly cry. This was one of only two occasions on which I saw a nun cry, and both were quite discomfiting; these two occasions were the only times I recall any monastic appearing overwhelmed by an emotion.

The other nuns seemed to ignore the tears; even if they noticed them falling, they certainly did not address them directly. One of the other nuns reassured the crying nun that sometimes she had similar feelings and that she understood how distracting they could be. The others weighed in with suggestions for other things to concentrate on to make the feeling go away, and this was the same approach that the counselor-nun took. She advised that under circumstances in which her emotions overwhelm her, she should draw on any of the many techniques taught at the monastery that serve to reign in thoughts and emotions. Like the nun who had given me meditation advice during the retreat, she recommended using the counting method in order to have something else upon which to focus. She also recommended that she nian fo (chant a buddha's name) or recite sutras she had memorized. (Everyone at the monastery, even the lay people, had memorized the Heart Sutra; monastics had memorized quite a few more.) Any of these methods would give her something to concentrate on to take the vehemence out of the feeling and enable her to reach past it.

Many monastics mentioned this set of skills that aid in overcoming emotions as one of the aspects of monastic life that they most appreciate. Before they renounced the world, monastics would sometimes feel overwhelmed by their own feelings; in the monastery they acquired the ability to free themselves of the burdens of strong emotion.

Unlike in other societies, where a calm exterior garners one respect if it suggests mastery over strong emotions, in the context of Taiwanese Buddhism a calm exterior ideally reveals that one has mastery not over the expression of emotion, but, more importantly, over whether one feels 
emotion at all. As I show below, their interest in not experiencing emotions comes from the belief that emotions are dangerous because they interfere with spiritual goals.

\section{Dangerous Emotions}

In this section I compare the threat posed by emotions in the monastic context with the perception that emotion is dangerous in other Chinese cultural contexts. Anthropologists who have looked at emotion in various Chinese cultural contexts have drawn different conclusions about whether Chinese consider emotions dangerous. I look at monastic stoicism in light of these discussions and argue that Taiwanese Buddhist monastics believe emotions interfere with the work of spiritual cultivation and they further believe that the burden of emotion falls more heavily on women. I demonstrate that with the important exception of compassion, emotions are thought of negatively and associated with femininity, whereas overcoming one's emotions is seen as masculine and as a sign of spiritual advancement. Monastics see compassion as the only emotion befitting a highly cultivated spiritual state and see the compassionate bodhisattva as the model not only for right action but also for right emotion.

\section{Dangerous Emotions in Rural China}

The monastic context is not unique in finding emotions dangerous. Anthropologists of Chinese societies have repeatedly raised questions about the possibility that Chinese consider emotions dangerous. Richard Solomon, for example, claims that the Chinese he studied believe feelings of hostility need to be concealed, especially when directed at authority figures, and that emotions are dangerous (Solomon 1971: 63, in Potter 1988: 195). Arthur Kleinman has also written extensively about the danger of "dysphoric" emotion and how Chinese somatize some emotions or psychological states rather than experiencing or expressing them as emotional: identifying as a headache or a tired feeling what someone in another society may describe as feelings of sadness or depression (1980). In her essay "The Cultural Construction of Emotion in Rural Chinese Social Life," Sulamith Heins Potter examines this literature in light of her own ethnographic research, and concludes that emotions are not as dangerous to Chinese people as many scholars have suggested. Potter found that her field subjects regularly spoke openly about their emotions 
but that such discourse had little weight; emotion was largely ignored as unimportant. In the Chinese context, she argues, unlike the American one, social institutions are not built on the emotions of those involved.

[T]he Chinese believe that experienced emotion is irrelevant either to the creation or to the perpetuation of social institutions of any kind. They certainly recognize the existence of emotions, and are aware of them as aspects of experience, but emotions are not thought of as significant in social relationships. An emotion is never the legitimizing rationale for any socially significant action, and there is no cultural theory that social structure rests on emotional ties. (1988: 185)

In this context, a wife can complain openly about her unhappiness in a marriage without threatening the social order, because marriage is not thought to be built on a foundation of emotions. Her sentiments towards her spouse bear little relationship to the success of her marriage if it is built on other things. One can also complain angrily about the grief caused by other social institutions, because no one expects social institutions to be built on, or to supply, positive feeling. Rather than the individual's personal feelings supporting the social order, Chinese may assume the social order will continue to exist without reference to inner feelings (1988: 194). Feelings are therefore personal and idiosyncratic rather than the foundations on which social institutions rest. Negative feelings cannot undermine that which was not expected to be built on positive feelings. According to Potter, although feelings are recognized, they do not carry the same weight or significance they do in American society. In contrast to the conclusions of Solomon and Kleinman, Potter finds that that her field subjects allow for the uncensored expression of negative emotions, but do not talk about them as they are not seen as relevant.

Potter draws a strong contrast between the insignificance of negative feelings and the weight given to emotions like love and affection which, she says, can be dangerous.

As an experienced emotion, love has the intrinsic capacity to lend importance to relationships, whether they have structural significance or not. Since the patterns of preexistent structure have primary importance in Chinese social relations, love is the rival and the potential enemy of structure. Rather than affirming structure, love is understood to endanger it. Thus, in Chinese terms, it is the emotion that most threatens the social order (1988: 199).

Potter describes the potential danger of affection in the Chinese context in an example where one might expect that affection would not 
likely undermine the relationship — the relationship between a father and a son. Affection is dangerous in this relationship because a father's open demonstration of his affection encourages his son to bridge the distance their relationship is supposed to maintain and defy the formalized patterns of respect and hierarchy on which their relationship is constituted. As Potter says, "If love is openly expressed, the form and strength of the relationship between father and son are thought to be damaged" (1988: 199). Unlike negative emotions, which Potter claims her field subjects do not give any weight to, love and affection are dangerous because they can lead to the crossing of distances necessary to maintain appropriate relationships.

Potter's argument is supported by other scholars of China. For example, in From the Soil: The Foundations of Chinese Society, Fei Xiaotong explains the "obvious indifference between husbands and wives" (1992 [1948]: 86) that he found in the countryside where, he says, the smooth functioning of a marital relationship requires little communication or affection. Friendship, affection, and intimacy are sought instead among one's peers. He argues that romantic or passionate $\operatorname{love}^{4}$ is a faulty ground for a relationship. The "struggle to achieve an unending love makes social relationships unstable" in part because it requires "continuously discovering and overcoming obstacles" (1992 [1948]: 91). Like Potter, Fei describes Chinese as treating this kind of feeling with suspicion, and not desiring it in a relationship that is expected to stand the test of time.

Fei describes the problem of love and affection as stemming from their interference with social institutions and work. When there is work to be done, "groups must maintain discipline, and discipline necessarily excludes personal sentiments" (Fei 1992 [1948]: 87). Fei further states,

in social relationships, such emotion can be used either for destructive or creative purposes. The immediacy and excitement of emotions change the original relationships. In other words, if one wants to maintain stable social relationships, one needs to avoid situations that cause emotional agitation. In fact, indifference is an indication of stable relationships (1992: 88).

Potter also writes that affection and love are problematic because they interfere with work; this causes issues because, to Chinese, work is the foundation of all social institutions. One can tell if a relationship is going well or ill by how well it accomplishes its work, and how each member describes the work of his or her partner, rather than by the feelings they describe having for one another. When the relationship is not a success, its 
failures are expressed in terms of a partner's inability or unwillingness to work, rather than as an emotional lack:

The villagers described a wide variety of other relationships, and in every case the capacity to work, rather than the capacity to feel, was what was significant. Their descriptions of relationships that they, themselves, thought of as close and loving were expressed as if the emotional aspects were not the relevant ones. Rather, they would recast the discussion in a form of emphasizing the willingness to work on the other's behalf (Potter 1988: 203).

Where Americans use the litmus of emotion to test the validity of a relationship, according to Potter, the idiom of work provides the terms by which Chinese discuss their relationships.

Fei makes a similar argument, that Chinese believe that relationships based on understanding (liaojie) rather than on emotions (ganqing) are more successful (1992: 88) To Fei, the significance of this "understanding" is that without it, one cannot get work done. For both authors, loving emotions interfere with work - therein lies their danger. Rather than seeing all emotions (or negative emotions) as dangerous, Potter and Fei both conclude that the danger stems from affection's potential to undermine social institutions and the proper functioning of relationships.

\section{Emotional Interference in a Taiwanese Monastery}

At Zhi Guang, monastics have already severed their relationships with their families. When they become monastics, they chujia, or leave home the expression chujia being a deeper expression of "leaving" that refers both to their change of residence and to their having broken off their familial relationships. Emotions cannot sustain or threaten relationships that no longer exist; if the threat of emotion in both Potter and Fei's examples is that it undermines the work of relationships, no such threat can (by chujia's definition) exist in the monastic context. Emotions do pose a threat here, although not to relationships. Although a Taiwanese monastery presents a very different cultural context than the rural mainland countryside described by Fei and Potter, the threat of emotions is not entirely dissimilar from that which they describe - in both cultural contexts, the fear is that emotions will interfere with work. For Potter, the threat is only posed by loving emotions, because she is looking explicitly at their effects on relationships; at the monastery, however, the threat is not 
to relationships, which have been severed. Nevertheless, all emotions pose a risk to monastics' ability to do the work required of them.

The main work of monastics is their spiritual cultivation. Their goal is to achieve a spiritual state where they can be free from the wheel of reincarnation. ${ }^{5}$ We are reincarnated, they believe, because we are still attached to the things, people, and experiences of the world, and we mistakenly believe these things provide happiness or satisfaction instead of the suffering that is truly at their root. As described above, monastics are working toward a calm state where they can gain greater spiritual insight, which will enable them to progress toward their goal. Monastics have many techniques to aid them in the spiritual cultivation which is their fulltime task. They believe emotions threaten the calm demeanor necessary to achieve spiritual goals because, when one is distracted by pleasure or pain, one finds it hard to concentrate on the task of spiritual cultivation. Rather than learning to concentrate despite the distractions, monastics are taught to rid themselves of such distractions altogether. Any distraction from their cultivation, whether a powerful emotion, such as the desperation of the nun described above to reach her spiritual goals, or merely the appearance of distraction, is problematic.

On one occasion while I was living at the monastery, the nun who ran the office in which I worked had to run some errands and she took another lay woman and me along. We ran an errand in town and then she drove us out to a nearby waterfall that she wanted me to see. When we got there, though, there were some sightseers, so she would not get out of the car. The lay woman and I only got out briefly because it was clear that the nun was not comfortable being there when others also were there. I asked the lay woman why the nun would not get out of the car. She explained that it would be unseemly for the nun to appear to be enjoying herself, having inappropriate fun. I also asked the nun, and she gave me the same answer. I did not think seeing a waterfall was very risqué, but they both told me that monastics are supposed to be constantly concerned with their cultivation and not distracted by anything, even something as innocuous as enjoying a waterfall. Even this simple pleasure, they felt, was inappropriate in a religious person who should neither show emotions nor appear distracted from the task of spiritual cultivation. ${ }^{6}$

For monastics, the threat of emotions may not be too dissimilar from that suggested by Potter and Fei. While emotions clearly do not pose the risk they do in other contexts, of getting in the way of the proper ordering of things and the work that establishes and maintains relationships, they do 
pose a risk in that they involve monastics in worldly distractions, keeping them from the work of their spiritual cultivation.

\section{Gendered Stoicism}

While maintaining a stoic appearance and mastery over emotions is important for all monastics, the monastics with whom I lived frequently explained to me that this was more challenging for nuns than monks. Taiwanese monastics believe women suffer greater emotional burdens than men, particularly before they become monastics. At the monastery, emotions are associated with women and with womanly behavior and are most often raised in the context of discussions of gender difference.

Assertions about women's emotionality are based in Buddhist texts read and studied at the monastery. Texts such as The Book of Gradual Sayings describe women as particularly susceptible to emotion:

In the morning a woman stays at home with heart haunted by the taint of stinginess. At noontide a woman stays at home with heart haunted by jealousy. At eventide she stays at home with heart haunted by sensuality and lust. These are the three qualities ... possessed of which womenfolk ... are reborn in Purgatory (in Paul 1985: 52-53).

Such beliefs about women were reiterated regularly by monastics. In the following passage from a tape-recorded interview with a nun who worked as a nurse before becoming a nun, she explains the preceding passage in her own words:

Women have three kinds of bad minds. As soon as they get up in the morning, they're greedy. That's the first point. They try to own all the things in the world. Second, they get jealous easily. And third is sexual desire or dependent minds. This means that women have a hunger for being protected or that women lust after handsome men more than men lust after women.

Examples of women's emotional failings are common in monastery teachings and in everyday discourse. The Master often corrected nuns for being emotional, and these stories were used to teach others. In one, the Master observed that a nun who was proud that she no longer acted emotionally was exhibiting pride, another emotion, and was therefore acting emotional like a woman. Nuns regularly described the women in their families, and themselves before they became nuns, as "ungenerous," "fragile," "soft," "tender," and "emotional." One well-educated nun who 
became a nun right after college, described the women in her family as well as herself as "emotional":

In my family all the women always feel agitated. Like when someone dies, we feel sad, you know, like a girl. I had two sisters, and between the three of us, our moods were manic-depressive. For example, during autumn, because the wind blows and the leaves fall, women feel sad. Also, when we see old people, we will feel sad if they're sick and there's nothing we can do. When I was in college, I used to feel very upset every time I had to leave home to go back to school... Girls, like me and my sisters, cry and feel sad, but not men. Men are steady in their emotions.

Another interviewee echoed this statement, saying, "women are more emotional and sensitive. They think differently from men."

At the monastery, women's emotionality is thought to stem in part from their bodies. A monk who worked at the monastery's construction office said:

Women originally suffer because of their bodies' structures. Their lives are harder because of this. For example, their monthly period is a hardship. Men don't have this problem; men are less likely to have physical problems.... Women also have more emotional problems. For example, if a woman is married and has children, this is also a hardship.

While some stressed the physical origins of women's emotionality, most described women's particularly strong ties to the world - the ties they are supposed to break in order to become monastics - as the source of their strong emotions. When still in the world, before renunciation, they said they would often bear the emotional burdens of others because of their ties. A senior nun who ran a branch temple told me about life before becoming a monastic:

Before becoming a nun, I had a boyfriend for over four years and I felt whatever he felt. If he was happy or sad, I felt it and it was a huge burden.... If you like someone ... you live for him. And I think this is a kind of burden, a kind of suffering.... A person can be good for you for a while, but then be bad for you.

The emotional burdens of familial ties were particularly problematic for women who had children before they decided to become monastics. Although in theory one would not be allowed to bring one's children to the monastery, many children of nuns (and some monks) were also resident monastics. Sometimes this was because once a child expressed an interest in being a monk or nun, his or her parents would decide that one or both of 
them should also join the monastery. Sometimes the child followed the parent who had made the decision first. Once at the monastery, their parental role should end, as children live separately from adults; severing family ties is the key element of renouncing the world and taking religious vows. Sometimes this break was not clear, however, as was the case with one nun, whose fifteen-year-old daughter was also a nun who befriended me. This mother-nun had brought her entire family with her to the monastery and, except for her husband (who regularly visited and volunteered at the temple), all had become monastics (including her four children, her siblings, her mother, and some of her aunts). Although she had renounced her ties to the world, she often had to fulfill her familial obligations, such as her role of mother to her children. She once approached me about teaching her daughter English (as had many parents when I previously lived in Taichung). As a monastic, she ideally should be free of such obligations and their concomitant emotions (such as desire for her child's happiness and success).

Leaving one's children behind does not guarantee a nun less emotional pain - as the story of one nun, who left behind an eight-year-old daughter, illustrates. "It took me more than two years to resolve to become a nun. It was not an easy decision to make because I had a family.... I knew if I came here it would hurt [my daughter]. Every time I thought about becoming a nun, I would think of her and cry." She ultimately concluded that her fate was to join the monastery, and that if she did not, she would regret it the rest of her life. "So I decided to give her up.... I loved her, and I also worried about her. We were knotted together and never would be untied since my feelings for her were very deep....When I first became a nun, I'd think of her and cry." However, she said that the pain of her decision to become a nun has eased with time, and she no longer thinks of her daughter as often. While she used to call regularly, she now thinks remaining in contact does neither of them any good. Leaving behind relationships, and the emotions that come from them, is necessary in order for monastics to achieve their spiritual goals. Since monastics believe women are more embroiled in relationships, they are thus more affected by emotion. However, this can change after they break off relationships, and have had time at the monastery, learning to feel emotions less.

Teachings and stories in the monastery regularly contrast exaggerated stereotypes of women (as emotional creatures) with those of men (who are better at not feeling emotions). Nuns frequently told me that they studied the behavior of monks as a model for their own actions. They believed that 
from monks they could learn how to sit still for long periods and how to be decisive, unafraid, and calm. While stoicism is the ideal for monastics, in both appearance and in essence, this ideal is also masculine.

\section{Cultivating Compassion}

In this final section, I show that Taiwanese Buddhist monastics use scarification as a means to reveal to the world that not only can they endure physical pain stoically, but also that they have the compassion necessary to fulfill the bodhisattva vow. Where a stoic countenance reveals that Taiwanese monastics have progressed spiritually to the point where they no longer are swayed by emotion, the scarification of their heads reveals that they have the compassion necessary to endure the suffering of the world. Enduring the pain of the scarification also effects a change in their lived experience of emotion. To explore both the semantic and transformative meanings of these scars, I examine them in light of recent discussions of language and emotion which suggest that speaking about emotions can be more than simply a reporting of an emotional state; the statements themselves can be transformative - changing one's way of being in the world. Recent anthropological scholarship suggests that speaking of emotions can take emotions from being individual and idiosyncratic, and make them objective, general, and less forceful. I argue that the reverse process is also true, that through scarification, an objective, esoteric concept like compassion can be burned into the body, concretizing and personalizing the feeling, and transforming scarred monastics' experience of the emotion of compassion as well as their way of being in the world.

\section{Masculine Compassion}

In addition to using the monks as a model for cultivating a stoic appearance, the nuns also see in the monks a model of exhibiting the right kind of feeling - compassion. For those more familiar with Western traditions, the association of compassion with men may seem odd as it is frequently seen as a feminine trait. In the West, masculine figures in myth and fiction (especially paternal figures) tend to be cold and rational, and feminine figures (especially maternal figures) are more often swayed by compassion. In contemporary American discourse, some argue that more women should be involved in public life because they are as capable as 
men; others argue that more women should be involved because they possess traits that are believed to be unique to women. When the genders are contrasted along this latter line of thought, men are described as quite dispassionate, whereas women are more compassionate. In theory, this compassion leads women in politics to work on children's issues and to be less inclined to send soldiers into battle. According to this theory, because women have children (or because they are more nurturing), they are more capable of feeling compassion than their more detached male counterparts.

The cibei (compassion) that is described at the monastery, unlike Western compassion that is thought to be aided by feelings of connection to family, is defined in contrast to the kinds of feelings that one has as a mother or as a nurturer. Rather than causing her to feel compassion broadly, the feelings that a woman has as a result of her connections to her family are thought to be selfish, preventing her from feeling a broader compassion for those outside her sphere. In this sense, women are described as having "narrow hearts" in that, as one nun said, "a woman ... only cares about beauty, her own children, about a small world." She contrasted this with the compassion of a Buddhist monk who reaches beyond his own circle and has "qualities like decency, purity; he has a pure mind and does good for others." One monk said that women are focused on their own smaller worlds and more narrow-hearted in that they "tend to be more jealous and envious [whereas] men's hearts are bigger." Although a woman can feel for others, monastics believe that in general, a woman's emotions center on her own sphere and are therefore selfish - even when her emotions are directed outward at someone else, that person tends still to be within her own sphere. On the other hand, men's compassion does not distinguish between the feelings of oneself, those in one's sphere, and those outside it.

A woman's lack of compassion is not thought to be a permanent condition. The nuns believe they can study and learn from men's examples how to keep down their own personal emotions and instead feel a broader compassion for humanity. Although women who are linked to the world tend to have their emotions wrapped up in it, they believe, women who detach from their own circles and personal emotions are able to develop this masculine, compassionate characteristic. This detachment is felt to be best accomplished by shedding one's ties to the world and becoming a nun. As one senior nun told me, "I feel I've changed a lot; my heart is more open. Since becoming a nun, I feel happier toward others without expecting anything back. I feel I've grown a compassionate heart." Where 
once she found herself embroiled in the emotions of her boyfriend and her family, having detached herself from those ties she is now able to feel more broadly compassionate to all.

As selfish emotion is typically associated with women and compassion is typically associated with men, at the monastery, having overcome one's selfish emotions and developed a compassionate heart also means that one is no longer thought to be a woman. In this context, women are defined by their emotionality and a woman who has overcome this problem - one who has accomplished the stoic appearance of a monastic and one who has developed a compassionate heart - is described as a man. For example, as one nun said, "We are women because we are greedy and noisy. If a female is open-hearted, kind, and compassionate, then she is a great man [nanren] of virtue."

Nuns clearly alter their outward appearance and look like men not only by copying their movements and their demeanor, but also by wearing the same clothes as the monks and through the manly shaving of their heads. Indeed, it can be very difficult to distinguish male monastics from female monastics. This serves several purposes, one of the most significant being that obscuring their gender will remove any sexual longing they could arouse in monks or other males. This obscurity also aids nuns in selfidentifying as men, which serves to reinforce their change of character. Outward appearances of stoic masculinity, though, are not as important as having developed the selfless compassion of men. As one nun explains,

I don't have hair and I don't beautify myself, so physically, I'm more like a man. But in Buddhism, we want a xin [heart/mind] like a man.... The xin is the most important part, not the clothes and that stuff.... Do you have wisdom, compassion, a calm inner state? If you have these three things then you can be called a da zhangf $u^{8}$ [heroic, or manly, man].... When we vow to be da zhangfu, that means we want to have wisdom, compassion, and a calm inner state like the Buddha. Everyone can be a Buddha.... No matter if you are a man or a woman you can be a Buddha.

This last point was central to much of the monastery's teachings. Although women are believed to be more emotional than men, monastics believe no one is limited by their gender or any other condition; men and women alike have within them the same Buddha nature. Although monastics believe men may more easily feel compassion because they are less enmeshed in the petty emotions of family life, they also believe that women can extricate themselves from their families and learn to be more 
compassionate. Once women have started down this path, they are understood to have become like men in their abilities, and are therefore called men.

\section{The Compassionate Bodhisattva}

The fundamental goal of monastics is to become bodhisattvas. A bodhisattva is someone who, through insight built on years of diligent spiritual cultivation (or from a sudden inspiration) achieves the ability to not be reincarnated. Though having freed him or her self from the wheel of reincarnation, this is also someone who does not use this ability. A bodhisattva is someone who vows not to leave the world until all sentient beings also attain liberation. The bodhisattva's willingness to take this vow signals compassion for all living things and a willingness to forgo one's own reward for the sake of teaching and liberating others. At Zhi Guang monastery, the bodhisattva vow is understood as expressing infinite ambition; the number of sentient beings is practically immeasurable and therefore the suffering one must thus undergo in order to help them all is likewise limitless.

As part of the transformative experience, the day before one takes the vows, a monastic undergoes a scar-burning ceremony in which three scars are burned into the forehead, just above the hairline. This is done by holding the lit end of incense sticks against the skin long enough to burn three permanent, coin-sized scars. For several months after the ceremony, the welt formed remains raised and covered with a scab. Occasionally lay people undergo the ceremony and have the scars burned into their inner elbows. One man I interviewed about the process said that it took more than six months for his scars to heal and they remained quite painful the entire time.

According to the monastery's Master, burning the scar is an integral part of the vow-taking process. In a speech he gave prior to the ceremony in the late 1990s, he said that burning the scar indicates the novices' yearning to attain spiritual goals. In this sense, it serves as a marker - a sign to others that one is willing to undergo the limitless suffering necessary to become (and be) a bodhisattva. It brands them, literally, as having started the journey to becoming bodhisattvas. The Master says, "The scars are a symbol of our yearning to liberate all beings. Burning the body is an indication of willingness to endure the bodhisattva path."

This visible sign of charred flesh represents one stage of spiritual 
advancement in which greater pain is inflicted upon more advanced practitioners. At each level one is supposed to show no sign of emotion, but instead should be motivated by compassion for others. The Master illustrates these sentiments with the frequently repeated saying "(one should make) the novice kneel in pain, beat the monk, and burn the bodhisattva." The ability to suffer through extensive, prolonged periods of kneeling signals one's ability to be a novice; enduring punches and slaps signals one's resilience as a monk; scars burned into the forehead signal one's advanced spiritual state as that of the compassionate bodhisattva. In this ceremony, by enduring the suffering and transferring the merit of the action to others, one has acted as a bodhisattva and exhibited compassion. One enters the ceremony with a desire to become a bodhisattva but only a hope that one has sufficient self-control and compassion to endure the ceremony. By going through the ceremony, one's identity shifts to that of a bodhisattva. This is both signaled by and accomplished through the burning of the scar. The transformation into a bodhisattva begins with the pain willingly endured out of compassion for the suffering of others.

Why is the endurance of pain so important? Because merely stating one's vows, according to the Master, is not enough:

We can't just say, "my thoughts are pure" or "my thoughts are those of a Buddha." Even if those statements are true, we need the action of burning to concretize it or it will not remain so. Burning the scars gives shape to the formless, shapeless path. Without it, we can't fully understand the wisdom of the Buddha.

With this statement, the Master implies that pain itself seems to communicate what language - what the words of the vows alone cannot. The pain "gives shape to the formless ... path." It signals to others an ability and willingness to suffer. Much has been written about the inability of words to communicate pain - that language cannot articulate the sensations and meanings of pain (Scarry 1985). Pain is beyond language. However, for the monastics I studied, pain seems not only to be difficult to communicate but to be itself a system of communication that communicates what language cannot.

Chan Buddhism emphasizes the notion that language cannot communicate ultimate truths. While all religions deal with this limitation of language in some form, for Chan, it is the central issue. This is demonstrated by the use of gong'an (koan in Japanese), language puzzles that promote insight by their seeming lack of sense. Perhaps the most recognizable example of gong'an is "what is the sound of one hand 
clapping?" The student whose master has presented such a puzzle is not supposed to answer the question directly, but rather to see the ultimate nature of reality through the question's unanswerable nature.

If language fails to communicate ultimate truths, then it makes sense that the words of vows would feel empty, that proclaiming one's desire to be a bodhisattva would not be enough to accomplish the act. In this context, actions certainly speak louder than words, but they also do more than effectively communicate meaning. In this context, pain seems to convey meanings words cannot articulate; it seems to function as another kind of language.

The scarification part of the ceremony may be without language, but it still seems to work much like one of J.L. Austin's (1962) speech acts. To explore the similarities, I turn now to recent literature that borrows from Austin's concept, to suggest that statements about emotion can be performative as well as descriptive; I then explore the ways in which the scarification ceremony may be similar to these statements.

\section{"Emotives" and "From Being to Becoming"}

In his book The Navigation of Feeling: A Framework for the History of Emotions, William Reddy (2001) suggests a conceptual framework for understanding what happens linguistically when the expression of emotion effects a change in the world. Exploring the potential application of Austin's descriptions of "constantive" and "performative" statements to statements about emotion, he finds that they fall short of capturing the true nature of emotional statements. Although the categorization of statements of emotion as constantive (along with statements like "I feel hungry") seems obvious, Reddy finds that the term does not quite fit - statements about emotion can have an effect on the world, and therefore have something in common with performatives, or statements that both cause something to happen and make reference to that change. If a wedding officiant says "I now pronounce you husband and wife," that officiant both transforms the status of the individuals involved from single to married and announces the change. Although statements about emotion appear merely to describe emotion (e.g. "I feel happy" appears to simply describe the way the speaker feels), sometimes, like performatives, they effect a change in the world. In this case, they change the speaker and his or her feelings. To capture this potential of emotional statements, he calls them "emotives." Reddy describes emotives as having the power to cause 
the speaker to feel a heightened experience of the emotion he or she is expressing (feeling happier for having described oneself as happy), or to feel like a hypocrite if expressing a feeling he or she is not actually experiencing.

Although she does not use Reddy's language, in a recent article, "From Being to Becoming: Nüshu and Sentiment in a Chinese Rural Community," Liu Fei-Wen (2004) explores the transformative effect of emotional expression found in nüshu (Chinese literature written in characters developed, and only used, by women). In this tradition, women express their personal experiences of emotional pain — for example, their feelings at being required to marry when terribly young, or to marry into a family that lives far from their own - in laments that link their own experiences to those of other women. Like Reddy, she suggests that to read the articulation of emotions as if their sole purpose is to reveal what is hidden inside is to miss a key aspect of what such statements accomplish. Liu argues that the speaking of emotion can do much more than just provide a statement about an emotion - it can change it:

Sentiment is not merely a carrier or marker of thought, power, or relationship but is also a flow of energy that acts on and engages the protagonists. Sentiment is not just part of human phenomenological experience but also plays an active role in the way lives are felt, articulated, and reflected (2004: 424).

The ways that articulating emotions changes them can be understood on the basic level of catharsis - by expressing emotion one reduces the amount of pain inside. This transformation, though, can be even more involved: "a complicated, dialectical process of building a new self that is intersubjectively nurtured so as to overwrite one's vulnerability" (2004: 430).

Where Reddy emphasizes the power of emotives to heighten feelings (among other possibilities), Liu argues that in the process of articulating them, the women she studied objectify and gain distance from powerful emotions that are personal and idiosyncratic. To Liu, the expression of feeling

may disentangle the tie between the sentiments felt and the subject who feels. This is so because expression lays its foundation on a materialized basis ... and, thus, objectifies the sentiments. To objectify, by definition, one must stand outside, which, in turn, creates an effect of alienation. Alienation then allows transposition of a felt emotion from self into a third space, in this way rendering terrible experiences bearable and manageable (2004: 430). 
As one of her informants says, expressing emotion toughens the skin and makes it less susceptible (2004: 430).

Perhaps, to turn the concept of emotives around and the work of Reddy and Liu on end, what happens in the scarification ceremony is something akin to the reverse of what happens for the women in Liu's study who use language to create distance between themselves and their personal, painful emotions. Where language allows Liu's lamenters to objectify and distance themselves from their pain, for the monastics in my study, pain is used to take something - an objective, distant, and esoteric concept like compassion - and make it a real, concrete, and powerful feeling that the body experiences through pain. In this sense, burning the scars has the opposite, but similarly transformative, effect of the laments of nüshu because it takes something general, abstract, and impersonal - the concept of compassion - and it makes it into a tangible bodily experience. The perfect compassion of the bodhisattva (cibei) is an abstract, esoteric concept and a difficult feeling to cultivate; cibei is a feeling quite different from pity or empathy. Cibei is achieved when one has transcended ordinary emotion and is able to feel for all sentient beings without discriminating. It may be understood in theory, but as difficult as the concept may be to fully grasp, it is that much harder to truly feel.

Where the meditation techniques described earlier enable monastics to learn to feel less, when it comes to compassion, the point is to learn to feel more. Although the bulk of their practice is focused on not experiencing emotion, compassion - which may be easier to conceptualize than to actually feel - is put into the body of monastics through the use of pain, which makes the experience real and concrete. Unlike the women using the laments of nüshu to voice their pain and thereby lessen it, with scarification, the goal is to heighten the feeling. Through scarification, one does the opposite of distancing and objectifying pain; pain is willingly taken into the body. One of the lamenters described by Liu says that lamenting toughened her skin and made it less susceptible; for monastics, though, susceptibility to the feeling of compassion is seared into skin through scarification.

In this ceremony, one willingly endures pain, and yet does not show any reaction to the pain. One remains stoic, and yet the scars remain after the ceremony - an emblem to those who see them of the compassion of the monastic who bears them. The stoicism shown during the scarification ritual reveals not a tremendous ability to restrain one's emotions, but rather a willingness to endure the limitless suffering of all sentient beings, a 
willingness born of deep compassion. The stoicism shown in this ritual reflects mastery over one's emotions, but also that one has accessed the deeper, more profound trait of compassion.

Scars are semiotic in that they communicate the willingness of the person to suffer on behalf of others in a way that is more powerful than could be done with mere language. The scarification further serves to create, heighten, or concretize the experience of compassion for monastics. Finally, scarification further accomplishes the act of making one into a bodhisattva; by enduring the pain and transferring the positive karmic merit accrued through the ceremony to others, they have actually started down the bodhisattva path. Although it does not use language, the scarification ceremony is not unlike a speech act in that it both states something and accomplishes it.

\section{Conclusion}

At Zhi Guang Shan, a stoic appearance and scars both hint at a complicated understanding of emotions that lie below the monastics' surface. Where most other anthropological studies of emotional mastery suggest that in other societies, it usually gains significance when a powerful emotion is constrained beneath a stoic appearance, in this context, its significance is quite the opposite. Because emotions disturb the calm state monastics need in order to achieve spiritual goals, monastics need to do more than control the appearance of emotion: they need to rid themselves of emotion altogether. Stoicism reflects that one has achieved a high level of spiritual cultivation. Stoicism shows that nuns have freed themselves from the petty emotional concerns of their small personal spheres and that they have compassion, like that of men. The outer appearance of stoicism reveals an inner accomplishment of freedom from emotional swings. This appearance is further reinforced with the scars of the bodhisattva vow, which reveal that one's own petty emotions, such as a desire to free oneself from pain, have been replaced by compassion for the suffering of others.

This compassion does not necessarily come easily. It requires that monastics distance themselves from self-concern and concern for only their circle of family, friends, and associates and instead feel equally for the whole world. The difficulty in feeling this emotion is overcome by the use of pain to instill into the body and make concrete what would otherwise be abstract. Scarring works the opposite of laments; rather than harden the skin against a feeling, it enables the feeling to penetrate the skin. In the 
process of scarification, one also begins down the path of the bodhisattva - in that moment, one begins suffering for others out of compassion, which is the task of the bodhisattva. The scars also do what words cannot; they tell of the depth of compassionate feeling the monastic has within compassion enough to not only vow to turn back from the escape that they have earned from the wheel of reincarnation (and to bear limitless suffering in the process), but also to undergo the current, physical suffering of the scars themselves.

\section{Notes}

1. I wish to thank the Foundation for Scholarly Exchange in Taipei, Taiwan, which funded the research for this project with a Fulbright grant. For insightful comments on an earlier version of this paper, I thank Paul Brodwin and Asian Anthropology's anonymous reviewers. I also thank Shanshan Du for thoughtful comments on the meaning of cibei, and, along with Paul DeBruler and Molly Robertson, for providing feedback on various drafts.

2. One particularly well-traveled anthropologist commented to me that in other parts of Asia, monastics seemed to be the most lighthearted members of their communities. Indeed, I once met a Tibetan monk in Darjeeling who was always smiling and was quite charming and funny. In the short time I was there I encountered him a number of times on the street and in restaurants, and he always had a quick remark or joke about why we kept running into each other. Based on similar experiences as well as tales of monks who teach using gongan (koans, or Zen riddles) in their teaching, I imagined my research to entail easily entering a community of warmhearted people and, like my anthropologist friend, I was initially surprised and put off by the stern look of most Taiwanese monastics.

3. A pseudonym.

4. His actual term is "Faustian love."

5. In the next section, I describe in greater detail the bodhisattva vow to remain in the world despite having achieved liberation.

6. Appearing earnest and not distracted by ordinary fun is particularly important in Taiwan where historical stereotypes and a few notorious present-day examples cause the general populace to doubt the sincerity of monastics. In a cultural context where filial piety is central to morality, the choice to chujia, to leave home and renounce one's ties to one's family, is morally suspect. Indeed as historian Susan Mann has demonstrated, in Qing era China, monks and nuns were suspected of licentious acts and leading morally debauched lives, and accused of leading otherwise decent women out of seclusion and into monasteries where they were said to participate in orgies (Mann 1997: 195). A 
popular expression of the era posited that of every ten nuns, nine were prostitutes and the other was mad.

Strains of this image persist in Taiwan, where most lay people I spoke with believed that most of those who choose the renunciant's life do so because they have no other choice. The image of monastics has recently improved somewhat, aided by the reserved public demeanors of monastics, but recent scandals and a few prominent figures have prevented the image from being completely redeemed. Part of the problem, particularly for nuns, is a recurring character type in historical dramas on television. These women (who one nun I spoke with called "silly nigus" - nigu being a traditional word for "nun" which has fallen out of favor largely because of these images), who are ostensibly nuns, act in ways monastics (and the larger Taiwanese community) find both silly — running, shouting, giggling, manipulating people and flirting - and immoral. One woman in particular (who shaved her head and dressed like a nun but whose credentials some of the people I spoke with in Taichung doubted) regularly appears on Taiwanese game shows, singing and acting in skits. This behavior clearly violates many monastic precepts and undermines the carefully constructed image of self-control that most monastics cultivate. The monastic image has also been affected by recent scandals, which have shown some monks to be con-artists, doctoring photos to show their bodies emitting light or hovering mid-air and swindling unsuspecting lay people out of millions of Taiwanese dollars. Even otherwise famous and respected leaders of large temples have been accused of brainwashing large groups into becoming monastics against their will and getting excessively involved not only in Taiwanese politics, but American politics as well.

7. The term xin can mean "heart" or "mind." I follow Margery Wolf (1985) and Hill Gates (1987) in translating this phrase as "narrow-hearted," because I don't believe the monastics are intending to say "narrow-minded." This expression is juxtaposed with having compassion rather than with having an open mind.

8. Nuns frequently used da zhangfu to describe the monastic ideal. Although it is held up as a model for both monks and nuns, it has specific masculine connotations (Levering 1992), and should not be read as a genderless ideal.

\section{References}

Abu-Lughod, Lila. 1986. Veiled Sentiments: Honor and Poetry in a Bedouin Society. Berkeley: University of California Press.

Austin, J.L. 1962. How to Do Things with Words. Cambridge, MA: Harvard University Press.

Fei Xiaotong. 1992 [1948]. From the Soil: The Foundations of Chinese Society. Berkeley: University of California Press. 
Gates, Hill. 1987. Chinese Working-Class Lives: Getting by in Taiwan. Ithaca, NY: Cornell University Press.

Kleinman, Arthur. 1980. Patients and Healers in the Context of Culture. Berkeley: University of California Press.

Levering, Miriam L. 1992. "Lin-chi (Rinzai) Ch' an and Gender: The Rhetoric of Equality and the Rhetoric of Heroism." In J. I. Cabezon, ed., Buddhism, Sexuality, and Gender. Pp. 137-158. Albany, NY: State University of New York Press.

Liu, Fei-Wen. 2004. "From Being to Becoming: Nüshu and Sentiments in a Chinese Rural Community." American Ethnologist 31(3): 422-439.

Lutz, Catherine A. 1988. Unnatural Emotions: Everyday Sentiments on a Micronesian Atoll and their Challenge to Western Theory. Chicago: University of Chicago Press.

Mann, Susan. 1997. Precious Records: Women in China's Long Eighteenth Century. Stanford: Stanford University Press.

Paul, Diana Y. 1985. Women in Buddhism: Images of the Feminine in Mahayana Tradition. Berkeley: Asian Humanities Press.

Potter, Sulamith Heins. 1988. "The Cultural Construction of Emotion in Rural Chinese Social Life." Ethos 16(2): 181-208.

Reddy, William. 2001. The Navigation of Feeling: A Framework for the History of Emotions. Cambridge: Cambridge University Press.

Rosaldo, Michelle Z. 1980. Knowledge and Passion: Ilongot Notions of Self and Social Life. Cambridge: Cambridge University Press.

Scarry, Elaine. 1985. The Body in Pain: The Making and Unmaking of the World. New York: Oxford University Press.

Solomon, Richard. 1971. Mao's Revolution and the Chinese Political Culture. Berkeley: University of California Press.

Wolf, Margery. 1985. Revolution Postponed: Women in Contemporary China. Stanford, CA: Stanford University Press. 